\title{
p21-activated kinase 4 regulation of endometrial cancer cell migration and invasion involves the ERK1/2 pathway mediated MMP-2 secretion
}

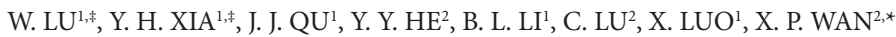 \\ ${ }^{1}$ Department of Obstetrics and Gynaecology, The International Peace Maternity \& Child Health Hospital, Shanghai Jiao Tong University, \\ Shanghai, P.R. China; ${ }^{2}$ Department of Obstetrics and Gynaecology, Shanghai First People's Hospital, Shanghai Jiao Tong University, Shanghai, \\ P.R. China \\ ${ }^{*}$ Correspondence: wanxp@sjtu.edu.cn \\ ${ }^{*}$ Contributed equally to this work.
}

Received January 5, 2013/ Accepted February 25, 2013

\begin{abstract}
Endometrial cancer (EC) is one of the most common malignancy of the female genital tract. Patients with metastatic disease have a poor prognosis. So far, however, the underlying molecular mechanisms of EC metastasis are largely unknown. P21-activated kinase 4 (Pak4) is important in cell motility and oncogenesis. Here we investigated a role of Pak4 in EC cell migration and invasion. Pak4 overexpression was observed in multiple human EC cell lines. In clinical samples, expression of total and phosphorylated Pak4 (Pak4 and p-Pak4, respectively) increased significantly with progression of EC from normal tissue to lymph node metastasis; both were positively correlated with depth of myometrial and vascular space invasion, lymph nodes metastasis, and poor histological differentiation. In two human EC cell lines, Pak4 overexpression promoted cell migration and invasion in vitro. Short hairpin RNA (shRNA)-mediated stable knockdown of Pak4 inhibited the metastatic potential of EC in an ERK1/2-MMP-2-dependent manner. These results suggest that Pak4 is an important regulator of EC cell migration and invasion. Therefore, Pak4 may be a promising target for the treatment of metastatic EC.
\end{abstract}

Key words: p21-activated kinase 4 (Pak4), endometrial cancer (EC), metastasis, migration, invasion, ERK1/2, MMP-2

Endometrial cancer is one of the most common gynecologic cancer and ranks as the fourth most common neoplasm and the eighth leading cause of death from cancer in females in the United States in 2011 [1]. And its incidence in China is on the rise [2]. The majority of endometrial cancers (72\%) are detected and treated at early disease stages (stages I-II), but once it has spread, it is almost impossible to eradicate[3]. Indeed, considerable number of patients with advanced and metastatic (stages III-IV) cancers have a poor prognosis with median survival often $<1$ year[4]. However, molecular mechanisms explaining the development and metastasis of EC are still unclear.

\footnotetext{
Abbreviations: EC, endometrial cancer; EGFR, epidermal growth factor receptor; ER $\alpha$, estrogen receptor alpha; ERK, extracellular signal-regulated kinases; LIMK1, LIM domain kinase 1; MMP-2, matrix metalloproteinase2; Pak4, p21-activated kinase 4; p-Pak4, phosphorylated Pak4; qRT-PCR, quantitative reverse transcriptase- polymerase chain reaction.
}

Cancer cell metastasis involves the invasion of primary tumor cells through the surrounding tissue and the extracellular matrix to distant sites, dynamic changes of the cytoskeleton are critical for this process[5]. It is well established that the Rho family GTPases Rho, Rac and Cdc42 regulate many of the processes required during metastasis through their interaction with downstream effector proteins[6]. In humans, the p21-activated kinases (Paks) are a family of serine/threonine kinases comprised of six isoforms (group I consists of pak1-3, and group II of pak 4-6) [7, 8], all of which are direct downstream effectors of Rac and Cdc42 in the regulation of cytoskeletal reorganization [9]. The group II member, Pak4 was first identified as an effector of activated Cdc42 [10]. Subsequent studies indicate that Pak4 binds to and phosphorylates several substrates that are involved in cytoskeletal reorgnization, including PDZ-RhoGEF and GEF-H1[11, 12], integrin $\beta 5[13,14]$, slingshot [15], LIM domain kinase 1 (LIMK1) and cofilin $[16,17]$. 
Pak4 is frequently overexpressed and/or activated in a variety of human cancer cell lines [17-22]. This overexpression and/or activation promote proliferation of ovarian cancer cells through the c-Src/EGFR pathway, and enhance migration and invasion in a c-Src/MEK-1/MMP dependent manner [18]. It promotes prostate cancer cell migration in response to hepatocyte growth factor (HGF)[17]. In athymic mice, overexpression of Pak4 also leads to tumor formation, whereas deletion of Pak4 inhibits tumorigenesis in vivo [23]. Taken together, these observations suggest that Pak4 may play a vital role in the initiation and progression of cancers. However, whether the metastasis of endometrial cancer is driven by dysregulated expression of Pak4 is not clear.

In the present study, we sought to investigate the expression pattern and the role of Pak4 in the migration and invasion of EC. The expression of Pak4 in EC tissues was assessed and correlated with clinicopathological parameters. We investigated also the potential role of Pak4 and its downstream pathways in EC cell migration and invasion. Our study identified Pak4 as a potential metastasis inducer of endometrial cancer.

\section{Materials and methods}

Patient specimens and immunohistochemistry analysis. Between December 2009 and November 2011, a total of 42 paraffin embedded samples of EC were collected from the Department of Pathology at the International Peace Maternity \& Child Health Hospital, which is affiliated with Shanghai Jiao Tong University, China. Patients with EC ranged from 44 to 78 years of age (mean $59 \mathrm{y}$ ); none had hormone therapy, radiotherapy, or chemotherapy before surgery. The diagnosis of each sample was assessed by pathologists according to the criteria of the International Federation of Gynecology and Obstetrics (FIGO).

Twenty-three normal endometrial samples from patients aged 27 to 64 years (mean $46 \mathrm{y}$ ) were obtained from patients who underwent a hysterectomy to treat other diseases, such as myoma or adenomyosis. Ten sections of endometrial hyperpalsia (5 without atypical cases and 5 with atypical cases) were collected from patients who had undergone hysteroscope examination due to irregular bleeding. The use of these samples was approved by the ethics committee of the Medical Faculty of Shanghai Jiao Tong University, China. All patients provided written informed consent.

Immunohistochemistry was performed on formalin-fixed paraffin sections. These were deparaffinized in xylene and hydrated through a graded series of alcohol to distilled water before antigen retrieval. Slides were subjected to antigen retrieval by boiling in citrate buffer ( $\mathrm{pH}$ 6.0) for $20 \mathrm{~min}$ then cooled to room temperature. Endogenous peroxidase was blocked by incubation in $0.3 \% \mathrm{H}_{2} \mathrm{O}_{2}$ in methanol for $30 \mathrm{~min}$. Nonspecific binding was blocked by incubating slides with $5 \%$ bovine serum albumin for $30 \mathrm{~min}$ at room temperature. Sections were incubated overnight at $4^{\circ} \mathrm{C}$ with primary antibodies used as follows: rabbit anti-Pak4 (1:100, Abcam, Cambridge,
MA, USA) and rabbit anti-p-Pak4 $\operatorname{Ser}^{474}$ (1:100, Cell Signaling Technology, Beverly, MA) [18]. Preimmune serum from the same species was used as a negative control. Subsequently, slides were incubated with biotinylated secondary antibody (MRBiotech, Emeryville, California, USA) for $10 \mathrm{~min}$.

The staining intensity was scored in the following manner: $0=$ negative, $1=$ weak, $2=$ moderate, $3=$ strong. The staining percentage was scored as: $0=0 \%$ to $5 \% ; 1=5 \%$ to $25 \% ; 2=25 \%$ to $50 \% ; 3=50 \%$ to $75 \%$; and $4=75 \%$ to $100 \%$. We obtained a composite histoscore by multiplying the values of the 2 parameters by a maximum of 12 .

Cell culture and isolation of human endometrial epithelial cells. Ishikawa, AN3CA, RL95-2, and SPEC-2 cells (American Type Culture Collection, Rockville, Md) were maintained in DMEM/F12 (1:1) (Gibco; Auckland, NZ) and supplemented with $10 \%$ fetal bovine serum (FBS) (HyClone, Logan, UT) in a $37{ }^{\circ} \mathrm{C}, 5 \% \mathrm{CO} 2$ incubator. For endometrial epithelial cell cultures, we obtained samples of human endometrium from 5 premenopausal, non-pregnant patients undergoing endometrial biopsy for menorrhagia. All specimens were confirmed as normal by histology analysis.

We used the methods of Zhang et al. [24] and Osteen et al. [25] to isolated the endometrial cells. Briefly, the tissue was cut into $2-3 \mathrm{~mm}^{3}$ pieces and incubated with $0.1 \%$ trypsin-EDTA for approximately $30 \mathrm{~min}$ at $37^{\circ} \mathrm{C}$. The suspension was then filtered through a $150 \mu \mathrm{m}$ sieve to remove mucous material and undigested tissue. The endometrial cells were separated by filtration through a $38 \mu \mathrm{m}$ sieve, which allows the stromal cells to pass through; the glands were recovered from the filter by backwashing with PBS. The separated endometrial cells were cultured in DMEM/F12 (1:1) supplemented with 10\% FBS.

Plasmid, transfection, and treatment with the ERK1/2 inhibitor. To stably express Pak4 in AN3CA and Ishikawa cells, the endometrial cells were transfected with Pak4 expressing vector or the control vector PEGFP-N1 (Clontech Laboratories, Palo Alto, CA) using Lipofectamine 2000 (Invitrogen, Carlsbad, CA), and then selected with G418 $(800 \mu \mathrm{g} / \mathrm{mL}$, SIGMA Chemical, St Louis, MO, USA). To stably silence Pak4, the cells were transfected with a set of shRNA constructs (GeneCopoeia, Germantown, MD) against human Pak4 or the scrambled control vector psiHIV-U6 (GeneCopoeia), and then selected with puromycin $(0.5 \mu \mathrm{g} / \mathrm{mL}$, SIGMA Chemical, St Louis, MO, USA).

EC cells were plated $24 \mathrm{~h}$ before treatment with the ERK1/2 inhibitor U0126 (20 $\mu \mathrm{M}$, Cell Signaling Technology), or vehicle (DMSO, 0.1\%). After $6 \mathrm{~h}$, they were harvested for real-time PCR and/or immunoblot analyses, and plated for migration and invasion assays $24 \mathrm{~h}$ after inhibitor treatment.

Real-time qRT-PCR. Total RNA was extracted from cancer cell lines using TRIzol reagent (Invitrogen, Carlsbad, CA). cDNA was reverse-transcribed from total RNA using Prime Script RT reagent Kit (TaKaRa Inc, Otsu, Japan). Real-time PCR was performed using SYBR Premix Ex Taq (TaKaRa Inc) and analyzed with an ABI Prism 7000 Sequence Detection System. The oligonucleotide primers used included: Pak4 
A

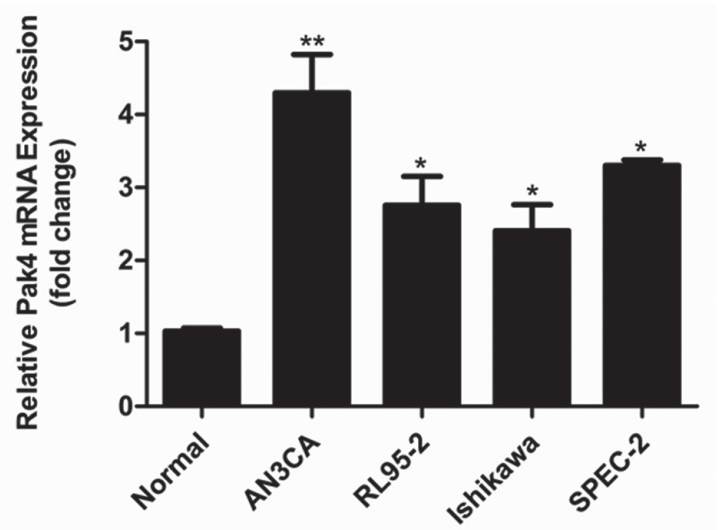

B

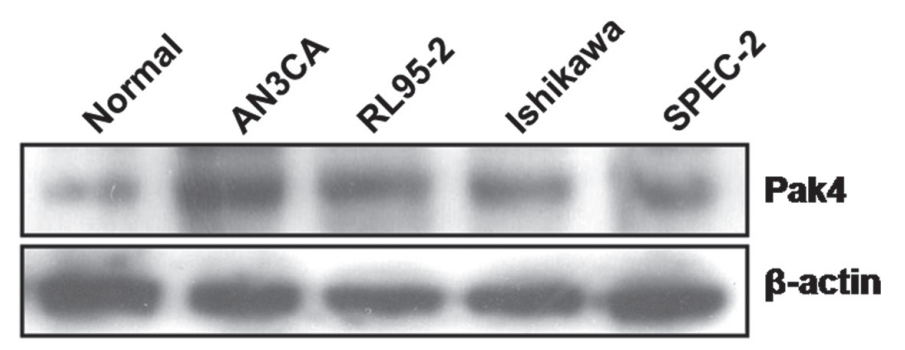

Figure 1. Overexpression of Pak4 in EC cell lines. (A) mRNA and (B) protein expression of Pak4 in primary cultured normal endometrial epithelial cells and endometrial cancer cell lines as determined by $\mathrm{qPCR}\left({ }^{*} \boldsymbol{P}<0.05,{ }^{* *} \boldsymbol{P}<0.01\right.$ compared with normal cells) and Western blot analysis, respectively.

forward: 5' -ATGTGGTGGAGATGTACAACAGCTA-3', reverse:5'-GTTCATCCTGGTGTGGGTGAC-3'; and $\beta$-actin forward: 5'-CAGCCATGTACGTTGCTATCCAGG-3', reverse: 5'-AGGTCCAGACGCAGGATGGCATG-3'. Gel electrophoresis was used to confirm PCR purity. For all the experiments, values on the $\mathrm{y}$-axis equaled $2^{(-\Delta \mathrm{Ct})}$, where $\Delta \mathrm{Ct}$ is the difference between gene $\mathrm{Ct}$ and normalized gene Ct. All data were obtained in triplicate in three independent experiments.

Western blot analysis. Cells were lysed using Extraction and Quantification ProteoJET Mammalian Cell Lysis Reagent (MBI Fermentas, Ontario, Canada) with a protease inhibitor cocktail (Roche Diagnostics, Basel, Switzerland). Total protein concentration was estimated using the BCA method (Pierce, Rockford, IL, USA). A total of $60 \mu \mathrm{g}$ protein was separated on a $10 \%$ sodium dodecyl sulfate-polyacrylamide gel and transferred to a polyvinylidene fluoride (PVDF) membrane. Membranes were incubated with primary antibodies. Signal was detected using BeyoECL Plus (Beyotime).

Primary antibodies included: rabbit anti-Pak4 (1:1000, Abcam), rabbit anti-p-Pak4 Ser474 (1:1000, Cell Signaling Technology), mouse anti- $\beta$-actin (1:2000, ProteinTech Group, Chicago, IL), rabbit anti-ERK1/2 (1:1000, Cell Signaling Technology), rabbit anti-p-ERK1/2 Thr202/Tyr204 (1:1000, Cell Signaling Technology).

In vitro migration and invasion assays. Cells were seeded in serum-free medium on the upper compartment of each transwell chamber at a density between $2 \times 10^{5}-1 \times 10^{6}$ cells $/ \mathrm{mL}$ $(200 \mu \mathrm{L} /$ chamber). The lower chamber was filled with $500 \mu \mathrm{L}$ culture medium containing $10 \%$ FBS. Cells were allowed to migrate through an $8 \mu \mathrm{m}$ pore size membrane or invade through a Matrigel-coated membrane. After $24 \mathrm{~h}$ of incubation, cells that had failed to invade were removed from the upper chamber. Those that were attached to the outside of the membrane were fixed and stained with 5\% crystal violet. Attached cells were lysed with $10 \%$ ethylic acid, and absorbance (proportional to the number of cells) was measured at $590 \mathrm{~nm}$.
Hoechst staining. Cells were seeded in 24-well plates. After 48 hours, cells were washed in PBS and fixed in $4 \%$ (wt/vol) paraformaldehyde for $16 \mathrm{~h}$ at $4{ }^{\circ} \mathrm{C}$. Cells were washed in PBS and permeabilized with $0.2 \%$ Triton X-100 for $20 \mathrm{~min}$ at room temperature. Permeabilized cells were treated then with Hoechst $33258(10 \mathrm{mg} / \mathrm{ml})$ for $30 \mathrm{~min}$ at room temperature. Photomicrographs of cells were taken under fluorescence at $\times 400$ magnification.

Enzyme-linked immunosorbent assay (ELISA) for determination of matrix metalloproteinase-2 (MMP-2). We used a double-sandwich enzyme-linked immunosorbent assay (ELISA) (Boster, Wuhan, China) to measure the amount of MMP-2 secreted in the culture medium. The minimum detectable concentration of MMP-2 was $156 \mathrm{pg} / \mathrm{ml}$. The intraand inter-assay coefficients of variation were $<10.14$ and 12.9 , respectively. We performed the analyses in duplicate, with the mean value used for subsequent calculations.

Statistical analysis. All statistical analyses were performed using SPSS 16.0 (Microsoft, Redmond, WA, USA) or Prism (GraphPad, San Diego, CA, USA). We performed each experiment at least three times. Where applicable, data are shown as mean \pm SD. The two-tailed Student's t test or Mann-Whitney $\mathrm{U}$ test were used for comparison of data between two groups. A P value $<0.05$ was considered statistically significant.

\section{Results}

Pak4 is overexpressed in human endometrial cancer cell lines. We used real-time qRT-PCR and immunoblotting to screen EC cell lines in which endogenous Pak 4 was expressed, and detected higher levels of Pak4 mRNA (Fig. 1A) and protein (Fig. 1B) in AN3CA, Ishikawa, RL95-2, and SPEC-2 EC cell lines compared with primary cultured normal endometrial epithelial cells. Ishikawa cells [26], which are derived from well-differentiated local endometrial adenocarcinoma, had relatively low Pak4 expression among cancer cell lines. In contrast, AN3CA cells [27] derived from undifferentiated 
metastatic endometrial adenocarcinoma had the highest expression of Pak4 mRNA and protein.

Pak4 and activated Pak4 expression is increased in endometrial cancer tissues. We next sought to assess whether Pak4 is commonly up-regulated in clinical samples. Immu- nohistochemistry showed that Pak4 and p-Pak4ser474 (its activated form) were expressed in the cytoplasm and nucleus of endometrial epithelial cells (Figs. 2A and 2B). Staining was weak or absent in normal endometrium. In contrast, we found mild nuclear and strong cytoplasmic Pak4 (Fig. 2A)
A

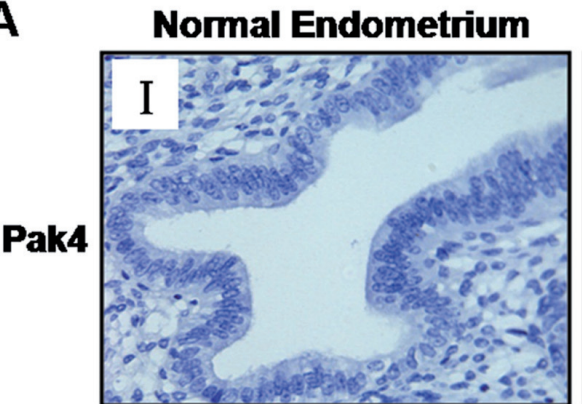

Serous Carcinoma

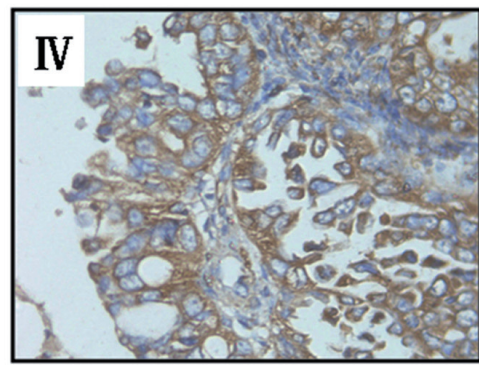

Atipical Hyperplasia

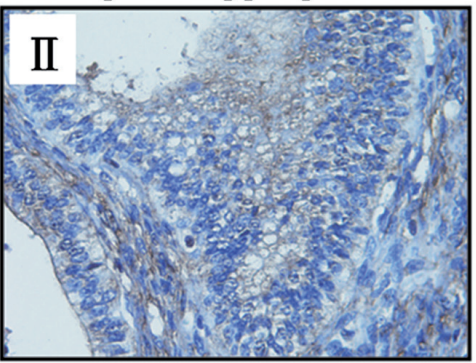

Clear Cell Carcinoma

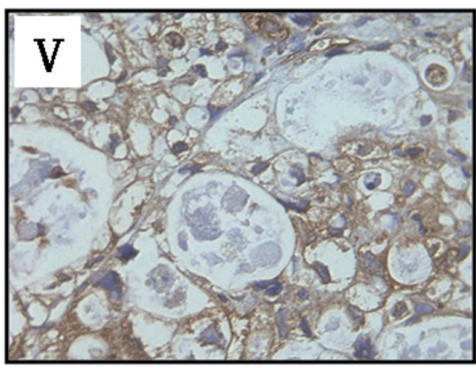

Endometrioid Carcinoma

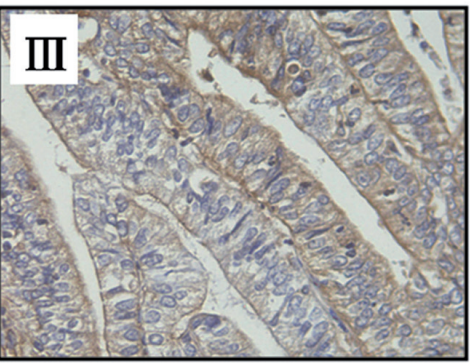

Lymph Node Metastasis

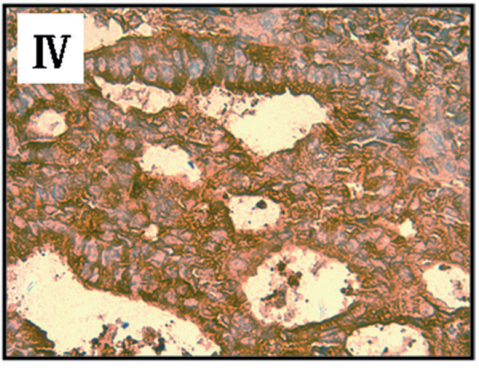

\section{B Normal Endometrium}

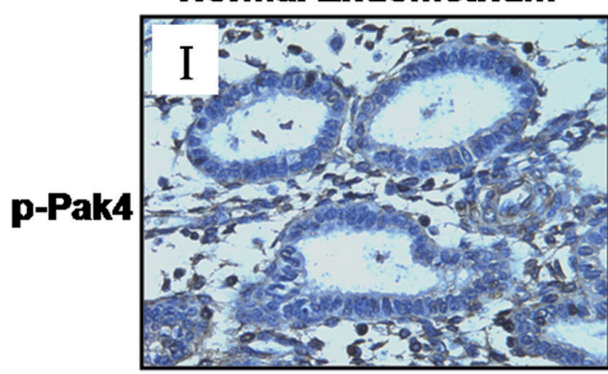

Serous Carcinoma

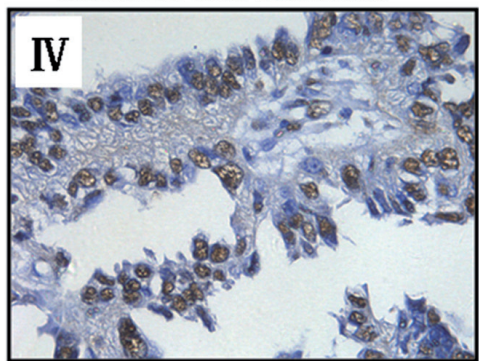

Atipical Hyperplasia
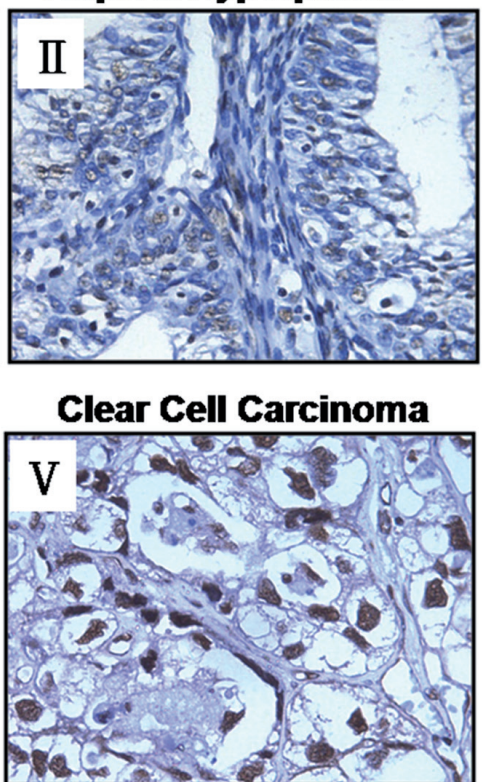

\section{Endometrioid Carcinoma}

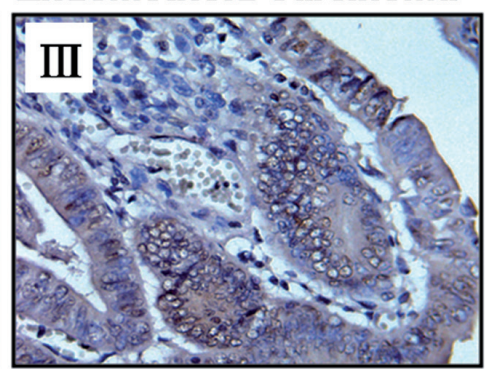

Lymph Node Metastasis

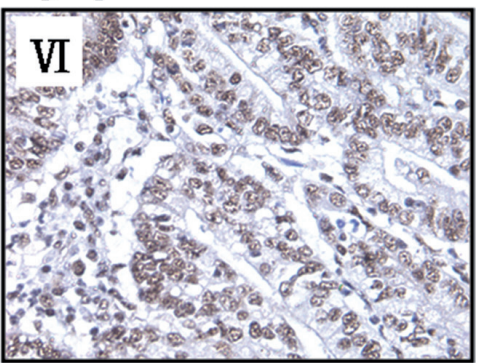

Figure 2. Overexpression of Pak4 and p-Pak4 in endometrial cancer tissues. (A) Pak4 and (B) Pak4 ${ }^{\text {ser474 }}$ immunohistochemical staining in normal endometrium, atypical hyperplasia, endometrioid endometrial carcinoma, serous carcinoma, clear cell carcinoma, and lymph node metastasis. Original magnifications, $\times 400$. 
as well as strong nuclear and moderate cytoplasmic p-Pak4 (Fig. 2B) immunostaining in atypical endometrial hyperplasia (the precursor of endometrioid carcinoma) and endometrial carcinoma tissues. EC that had metastasized to pelvic lymph nodes had the highest Pak4 and p-Pak4 expression (Figs. 2A and $2 \mathrm{~B})$.

We calculated a composite histoscore (percentage epithelium stained $\times$ stain intensity) to account for both stain intensity and uniformity. Cytoplasmic Pak4 and nuclear p-Pak4 staining (histoscore) progressively increased in the epithelial cells of atypical endometrial hyperplasia, invasive carcinomas, and lymph node metastases relative to the normal endometrium $(P<0.001$; Table 1$)$.

Further exploration of the correlation between Pak4 and p-Pak4 expression levels and clinicopathological parameters in endometrial carcinomas indicated a significant association between increased cytoplasmic Pak4 and nuclear p-Pak4 expression and the depth of myometrial invasion, vascular space invasion, lymph nodes metastasis, advanced disease stage (stages III and IV), and poor histological differentiation (grade 3) (all $P<0.05$; Table 1). However, there was no significant difference in either Pak4 or p-Pak4 expression between endometrioid and non-endometrioid (serous and clear cell histological subtypes) endometrial carcinomas ( $P=0.131$ and 0.056 , respectively; Table. 1 ).

Together, these data indicate that Pak4 expression is specifically increased in the most advanced lesions, suggesting that overexpression and/or activation of Pak4 contributes to malignant progression of human EC.

Overexpression of Pak4 promotes endometrial cancer cell migration and invasion. Immunohistochemical staining showed that Pak4 expression was associated with the progression of EC. To investigate the potential role of Pak4 in EC cell migration and invasion, AN3CA and Ishikawa cells were stably transfected with Pak4 expressing vector or control vector. Ectopic expression of Pak4 in stably transfected AN3CA and Ishikawa was confirmed by real-time qRT-PCR and immunoblotting (Fig $3 \mathrm{~A}$ and $3 \mathrm{~B}$ ).

Table 1. Correlation of Pak4 and p-Pak4 $4^{\mathrm{Ser} 474}$ expression with clinicopathological parameters in endometrial carcinomas.

\begin{tabular}{|c|c|c|c|c|c|}
\hline \multirow[b]{2}{*}{ Characteristics } & \multirow[b]{2}{*}{ Case $(n)$} & \multicolumn{2}{|c|}{ Pak4 Histoscores } & \multicolumn{2}{|c|}{ p-Pak4 $4^{\text {Ser474 }}$ Histoscores } \\
\hline & & Mean \pm SD & $P$ value & Mean \pm SD & $P$ value \\
\hline \multicolumn{6}{|l|}{ Diagnostic categories } \\
\hline Normal & 23 & $4.00 \pm 2.88$ & & $2.87 \pm 2.28$ & \\
\hline Hyperplasia without atypical & 5 & $4.00 \pm 1.23$ & & $3.20 \pm 0.45$ & \\
\hline Hyperplasia with atypical & 5 & $7.20 \pm 1.10$ & & $6.80 \pm 1.10$ & \\
\hline Carcinomas & 32 & $9.69 \pm 2.83$ & & $8.81 \pm 3.04$ & \\
\hline Lymph node metastasis* & 10 & $12.00 \pm 0.00$ & $<0.001^{\mathrm{a}}$ & $11.60 \pm 1.27$ & $<0.001^{\mathrm{a}}$ \\
\hline \multicolumn{6}{|l|}{ Age } \\
\hline$<60$ & 19 & $9.58 \pm 3.02$ & & $8.95 \pm 3.42$ & \\
\hline$\geq 60$ & 13 & $9.85 \pm 2.64$ & $0.880^{\mathrm{b}}$ & $8.62 \pm 2.50$ & $0.570^{\mathrm{b}}$ \\
\hline \multicolumn{6}{|l|}{ Histology } \\
\hline Endometrioid & 24 & $9.25 \pm 3.00$ & & $8.25 \pm 3.14$ & \\
\hline Non-endometrioid (serous/clear) & 8 & $11.00 \pm 1.85$ & $0.131^{\mathrm{b}}$ & $10.50 \pm 2.07$ & $0.056^{\mathrm{b}}$ \\
\hline \multicolumn{6}{|l|}{ FIGO stage } \\
\hline Early (I-II) & 24 & $8.92 \pm 2.89$ & & $7.75 \pm 2.79$ & \\
\hline Late (III-IV) & 8 & $12.00 \pm 0.00$ & $0.003^{\mathrm{b}}$ & $12.00 \pm 0.00$ & $0.001^{\mathrm{b}}$ \\
\hline \multicolumn{6}{|l|}{ Histological grade } \\
\hline Low (1-2) & 16 & $8.12 \pm 2.96$ & & $6.63 \pm 2.39$ & \\
\hline High (3) & 16 & $11.25 \pm 1.61$ & $0.001^{\mathrm{b}}$ & $11.00 \pm 1.79$ & $0.001^{\mathrm{b}}$ \\
\hline \multicolumn{6}{|l|}{ Myometrial invasion } \\
\hline$\leq 1 / 2$ & 27 & $9.26 \pm 2.89$ & & $8.22 \pm 2.95$ & \\
\hline$>1 / 2$ & 5 & $12.00 \pm 0.00$ & $0.029^{\mathrm{b}}$ & $12.00 \pm 0.00$ & $0.009^{\mathrm{b}}$ \\
\hline \multicolumn{6}{|l|}{ Involving cervix } \\
\hline Negative & 27 & $9.41 \pm 2.93$ & & $8.59 \pm 3.08$ & \\
\hline Positive & 5 & $11.20 \pm 1.79$ & $0.181^{\mathrm{b}}$ & $10.00 \pm 2.83$ & $0.379^{\mathrm{b}}$ \\
\hline \multicolumn{6}{|l|}{ Vascular space invasion } \\
\hline Negative & 18 & $8.78 \pm 3.15$ & & $7.44 \pm 2.81$ & \\
\hline Positive & 14 & $10.86 \pm 1.88$ & $0.046^{\mathrm{b}}$ & $10.57 \pm 2.41$ & $0.005^{\mathrm{b}}$ \\
\hline
\end{tabular}

Significance of difference ( $P$ value) between categories was analyzed by ${ }^{2}$ Kruskal-Wallis rank test and ${ }^{\mathrm{b}} \mathrm{Mann}$-Whitney $\mathrm{U}$ test respectively. Those with significant $P$ values were underlined.

${ }^{*} 10$ total specimens from 8 patients 
A

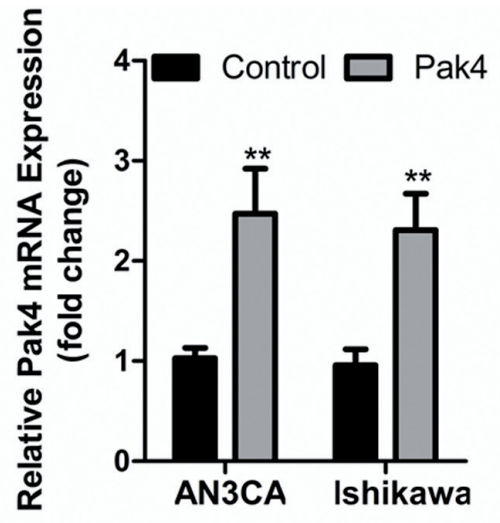

C
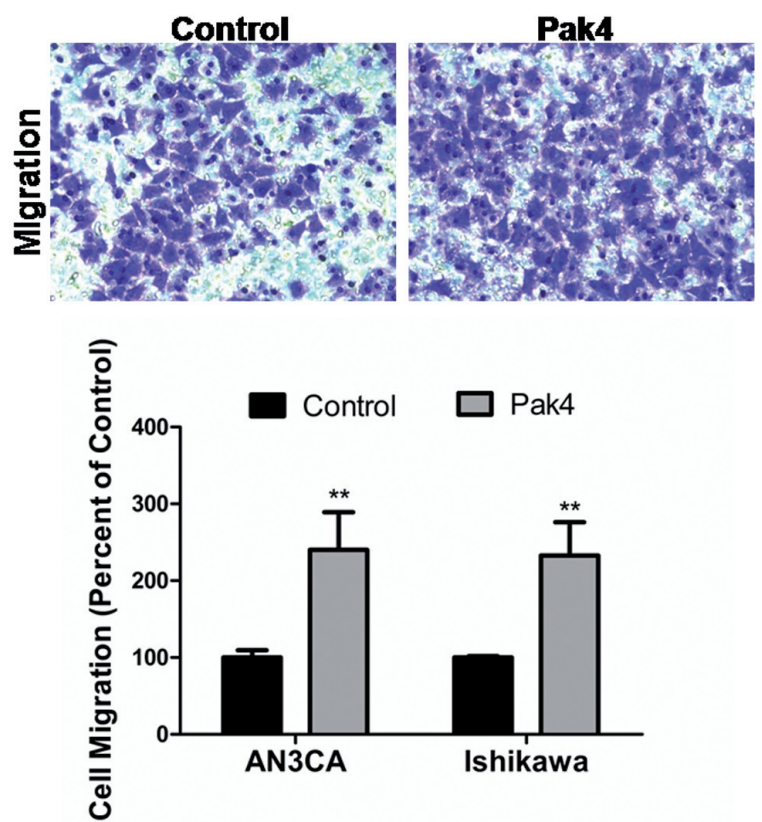

$\mathbf{E}$

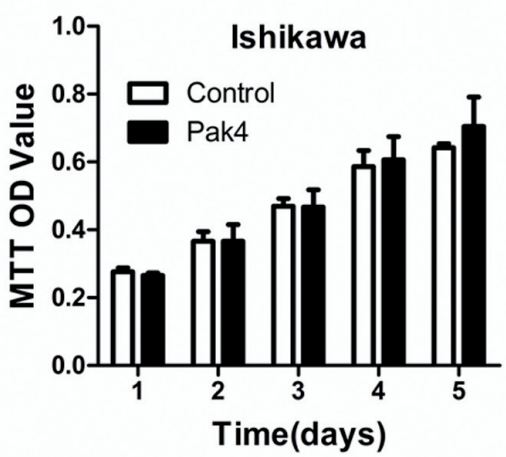

B

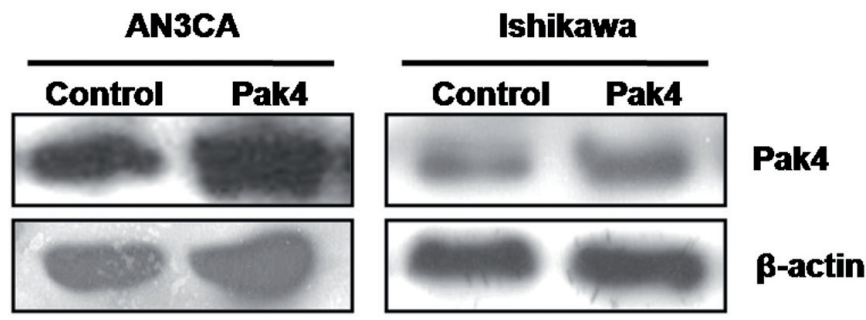

D
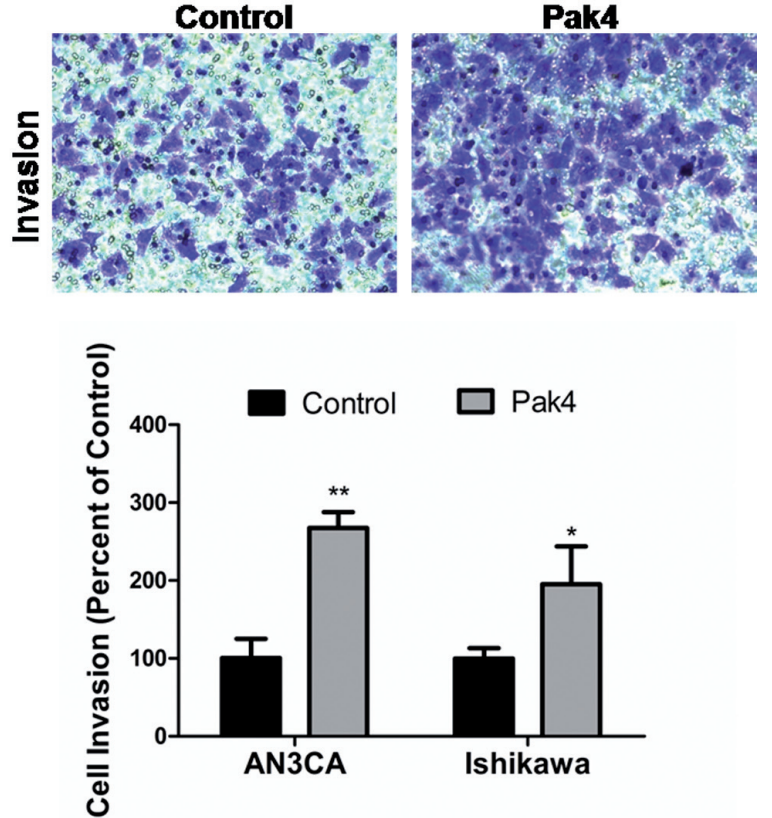

$\mathbf{F}$

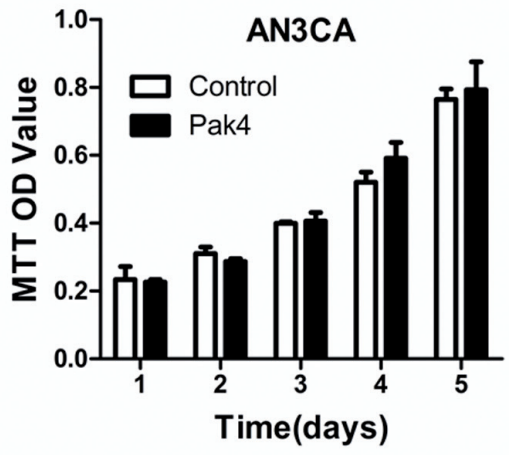

Figure 3. Overexpressed Pak4 promotes EC cell migration and invasion. (A) mRNA and (B) protein expression of Pak4 were measured in Pak4 stable overexpression AN3CA and Ishikawa cells by $\mathrm{QPCR}$ and Western blot analysis, respectively; ${ }^{* *} P<0.01$. (C) In vitro migration and (D) invasion assays using Transwell membrane without or with Matrigel coating, respectively. (Upper) Representative images of migrating or invading cells (magnification, $\times 200$ ). (Lower) Cell migration or invasion presented as percentage of control, OD values of permeated cells eluted in $10 \%$ ethylic acid elution were compared; $n=3 ;{ }^{\star} P<0.05,{ }^{\star *} \boldsymbol{P}<0.01$. (E and F) MTT assays were performed to examine cellular proliferation. There was no difference between Ishikawa and AN3CA cells transfected with control vector and Pak4 expression vector within 5 days. 
The transwell migration and invasion assays were performed to study the migratory and invasive ability of EC cells. As shown in Fig 3C, the numbers of migrated cells of AN3CA and Ishikawa cells transfected with Pak4 were increased more than 2-fold as compared with cells transfected with control vectors $(P<0.01, P<0.01)$. In addition, stable overexpression of Pak4 in AN3CA and Ishikawa cells also significantly increased cell invasion by more than 2 -fold $(P<0.01, P<0.05$; Fig 3D).

To determine whether overexpression of Pak4 also induced cell proliferation, 3-(4,5-dimethylthiazol-2-yl)-2,5-diphenyltetrazolium bromide (MTT) assays were performed. No statistical significance of induction of cell proliferation was detected between the Pak4 overexpression EC cells versus the control transfections within 5 days (Fig. 3E and 3F).

Knockdown of Pak4 inhibits endometrial cancer cell migration and invasion. To further investigate the effect of Pak4 on EC cell migration and invasion, we performed short hairpin RNAs (shRNA)-mediated stable knockdown of Pak4 in AN3CA and Ishikawa cells. The commercial plasmid psiHIV-U6 contains an inserted shRNA sequence that can either suppress the expression of Pak4 (ShPak4- psiHIV-U6) or is invalid (shiv- psiHIV-U6). As shown in Fig 4A and 4B, the shRNA led to an almost complete loss of Pak4 in EC cell lines compared to the scrambled control cells.

We used transwell migration and invasion assays to identify defective migration (Fig. 4C) and invasion (Fig. 4D) of Pak4 knockdown AN3CA and Ishikawa cells. The numbers of migrated cells of Pak4 knockdown AN3CA and Ishikawa cells were decreased nearly 2 -fold as compared with scrambled control cells $(P<0.01, P<0.01)$. Similarly, knockdown of Pak4 in AN3CA and Ishikawa cells significantly decreased cell invasion by more than 3 -fold $(P<0.001, P<0.001)$.

Next, we sought to examine the effect of Pak4 on cell apoptosis. As shown in Fig 4E, there was no significant difference in the proportion of apoptotic cells in Ishikawa after Pak4knockdown under regular culture conditions, as determined by Hoechst staining.

These results exhibit a functional role for Pak4 in mediating migration and invasion in EC cells and suggest a mechanism by which overexpression of Pak4 may contribute to metastasis of EC.

Pak4 regulates endometrial cancer cell migration and invasion through ERK1/2-mediated MMP-2 secretion. To investigate the molecular mechanism of Pak4-mediated migration and invasion in the AN3CA and Ishikawa EC cell lines, activation of ERK1/2 was determined using Western blot. Fig5 A and 5B show that ERK1/2 activity was induced together with MMP-2 secretion. Whereas knockdown of Pak4 caused a marked reduction in ERK1/2 activity, although we found no change in total ERK1/2 protein (Fig 5C). MMP-2 protein level was also reduced in shPak4 AN3CA and Ishikawa cells in conditioned media (Fig 5D) $(P<0.01)$.

To test if MMP-2 secretion is controlled by the ERK1/2 pathway in EC cells, we treated AN3CA and Ishikawa cells with ERK1/2 inhibitor U0126. As Fig 5E shows, MMP-2 secretion was significantly reduced by U0126 treatment of EC cells $(P<0.001)$. Moreover, U0126 attenuated both basal and Pak4-induced cell migration and invasion (Fig. 5F). These findings indicate that Pak4 promotes cell migration and invasion through ERK1/2-mediated MMP-2 secretion.

\section{Discussion}

Pak4 is overexpressed and/or activated in various human cancer cell lines, such as the lung, ovary, colon, breast, and prostate cells $[18,20,28]$. However, the Pak4 protein expression or activity in endometrial cancer is still unclear. In this study, we demonstrated that Pak4 and activated Pak4 expression are significantly increased in atypical endometrial hyperplasia and invasive cancers compared with normal endometrium. Both are even higher in lymph node metastases. More importantly, we found a significantly positive correlation between Pak4 and p-Pak4 expression with depth of myometrial invasion, vascular space invasion, lymph nodes metastasis, disease stage, and poor histological differentiation of endometrial cancer, all of which are important prognostic factors [29-31]. These data indicate that overexpression and/or activation of Pak4 contribute to accelerated progression of human endometrial cancer.

In clinical samples, we did not find significantly different Pak4 expression between endometrioid and non-endometrioid endometrial carcinomas. Non-endometrioid endometrial carcinomas (mostly serous and clear-cell morphology) display distinctive gene-expression profiles and behave in an aggressive manner [32]. Future studies are needed to determine whether Pak 4 also plays an important role in tumor progression using non-endometrioid carcinoma-derived cells as a model.

At the subcellular level, we have also observed mild nuclear and strong cytoplasmic Pak4 as well as strong nuclear and moderate cytoplasmic p-Pak4 immunoreactivity in endometrial cancer tissues. The Pak4 and p-Pak4 nuclear localization has also been found in endometrioid ovarian cancer using the same antibodies [18]. The same study also reported two Pak4 NLS (nuclear localization signal) which might be responsible for Pak4 nuclear accumulation. The nuclear localization of Pak4 suggests that this protein could be involved in the regulation of gene transcription. Pak6, another group II Pak, has been shown to bind to the nuclear hormone receptors, $\mathrm{AR}$ (androgen receptor) and ER $\alpha$ (estrogen receptor $\alpha$ ), and modulate gene transcription[33]. Increasing evidence suggests that cross-talk between ER and signal transduction pathways is an important factor in the growth of ER-positive EC cells and endocrine resistance $[32,34]$. This raises the possibility that Pak4 might affect ER transactivation in an estrogen-independent manner and, in principle, could contribute to the development of hormone independence. However, whether Pak4 is involved in ER regulated gene transcription needs to be further determined. 


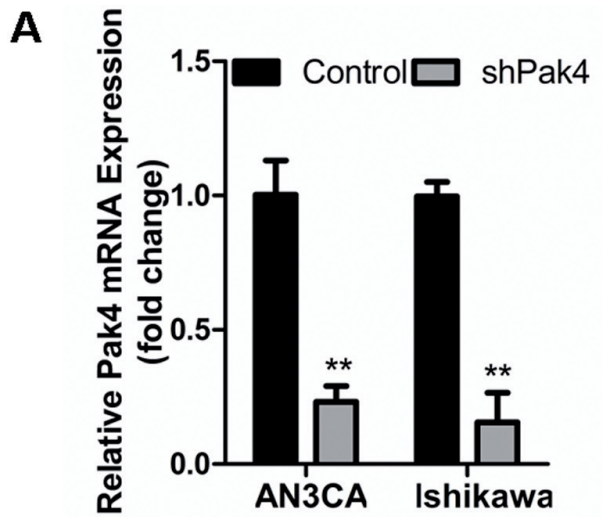

C
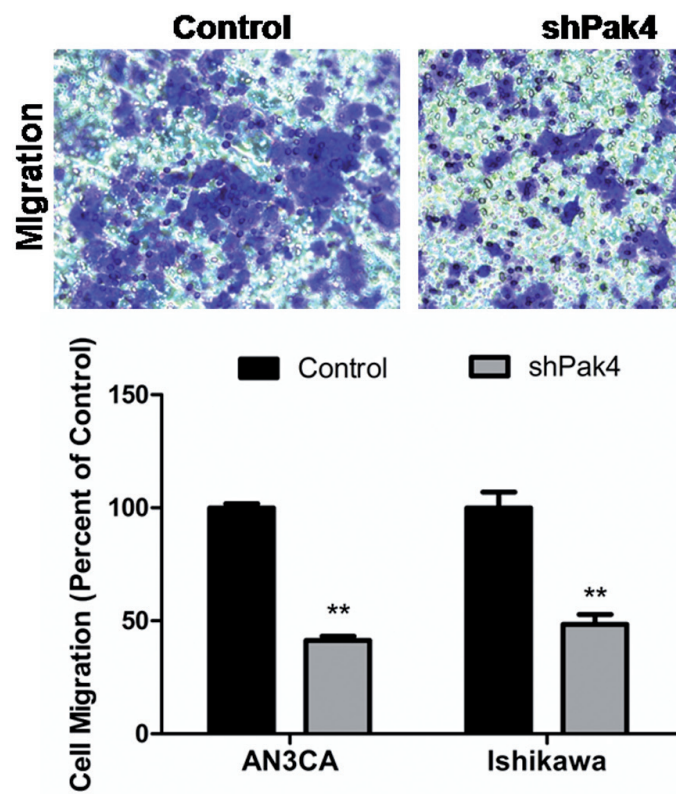

$\mathbf{E}$

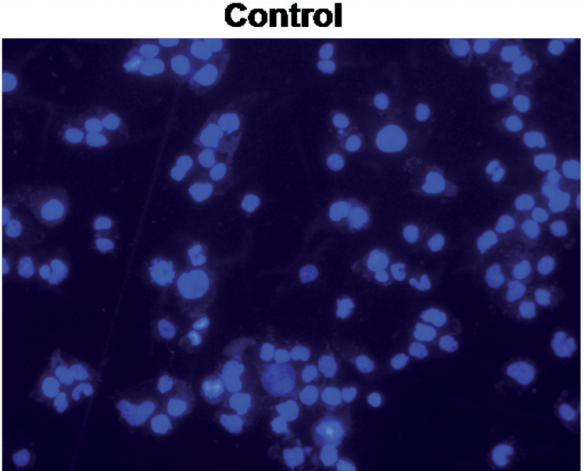

B

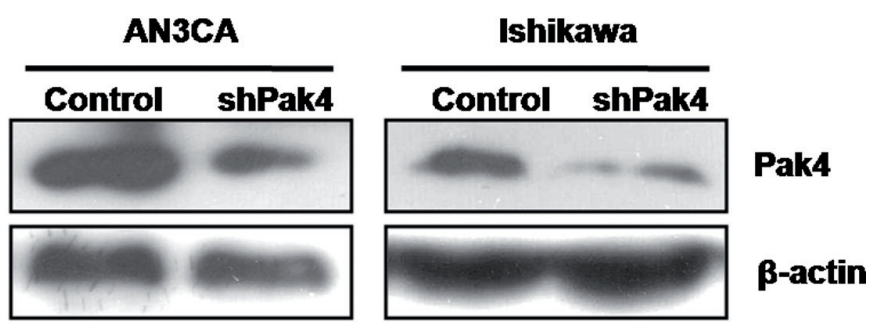

D
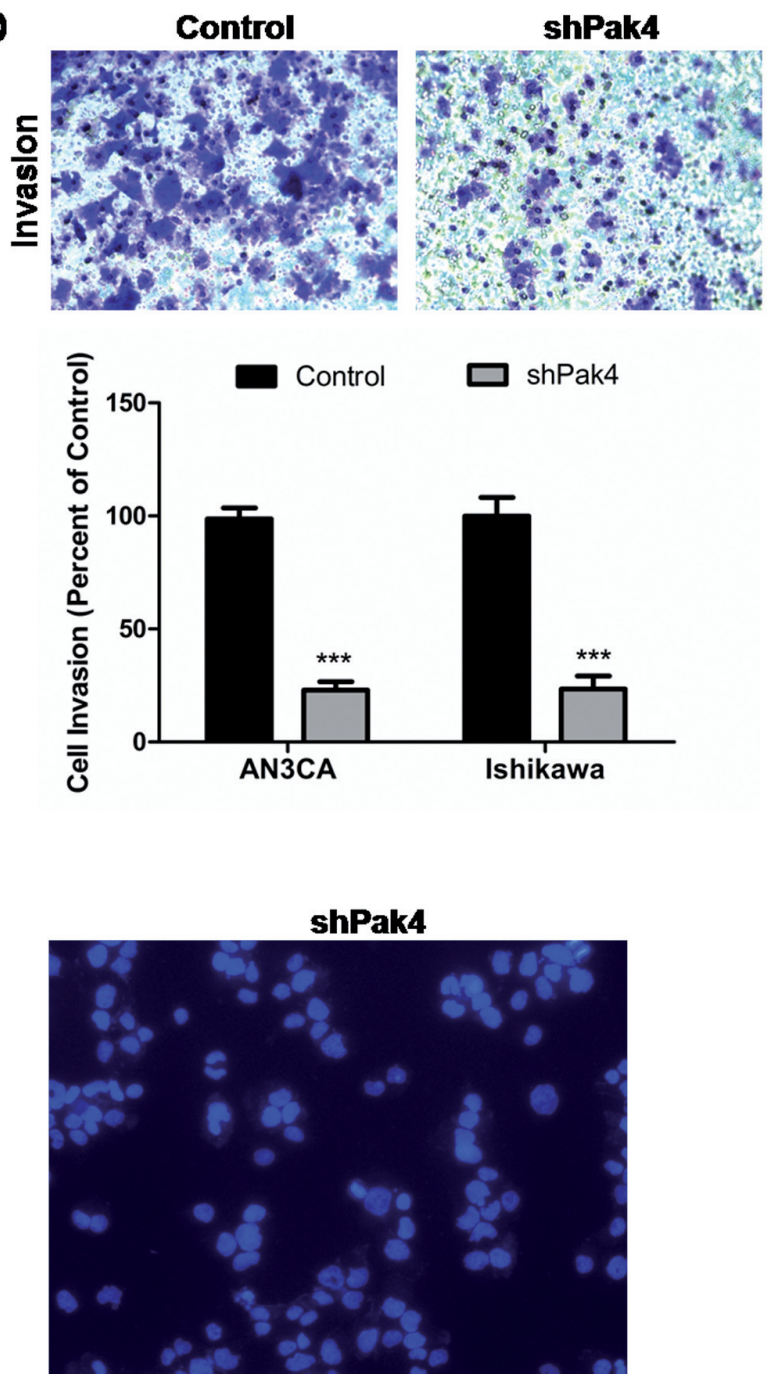

Figure 4. Knockdown of Pak4 reduces EC cell migration and invasion. (A) mRNA and (B) protein expression of Pak4 were measured in AN3CA and Ishikawa cells stably transfected with shRNA constructs (shPak4) or scrambled control vector (control) by qPCR and Western blot analysis, respectively; ${ }^{*} P<0.01$. (C) Significantly reduced migration and (D) invasion were observed in Pak4 knockdown EC cells compared with cells transfected with scrambled control. These are shown as representative images (upper) and bar charts (lower); $n=3 ;{ }^{* *} P<0.01,{ }^{* * * P<0.001}$. (E) Knockdown of Pak4 had no significant effect on apoptosis under regular culture conditions. Nuclear condensation was detected by fluorescence microscopy analysis of control and Pak4-expressing Ishikawa cells stained with Hoechst 33258. 
Outcomes show that Pak4 enhances cell migration and invasion of endometrial cancer cell lines. Dynamic cytoskeletal changes are required for cell motility and invasion by cancer cells [5]. Pak4 expression was first reported to induce filopodium formation downstream of Cdc42 [10]. Subsequent studies have revealed that Pak4 also contributes to actin organization and cell-substratum adhesion by phosphorylation of LIMK1 and cofilin [17]. This occurs by inducing cell rounding $[35,36]$ and interaction with Integrin $\alpha v \beta 5$ clustering [37], all of which are involved in mediating the spread of malignant neoplasms. Indeed, Pak4-knockout and -knockdown cells have significantly impaired migration and invasion [17-19]. Activated Pak4 induces a loss of focal adhesions [35], and cells isolated from $\mathrm{Pak}^{-/-}$mice have increased focal adhesions
[38]. Our experiments investigating the mechanism by which Pak4 regulates endometrial cancer cell migration and invasion indicate the involvement of Pak4 in the ERK1/2 and MMP-2 pathways. This is consistent with its role in ovarian cancer migration and invasion [18]. This pathway is intimately linked with cell-ECM (extracellular matrix) adhesion complexes essential for cancer cell metastasis $[39,40]$. The same study also showed that Pak4 significantly induced ovarian cancer cell proliferation after 12 days [18]. Pak1 is also involved in the regulation of cell cycle progression, and plays a role in oncogenesis by affecting cell proliferation[41]. In this study, no statistical significance of induction of cell proliferation was detected in Pak4 overexpression EC cell lines within 5 days. Further studies are needed to elucidate the mechanisms and
A
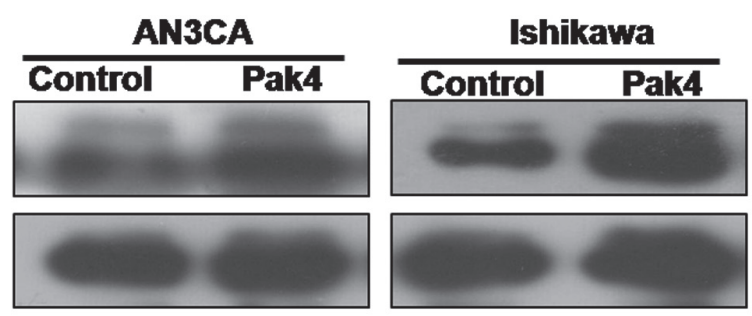

C
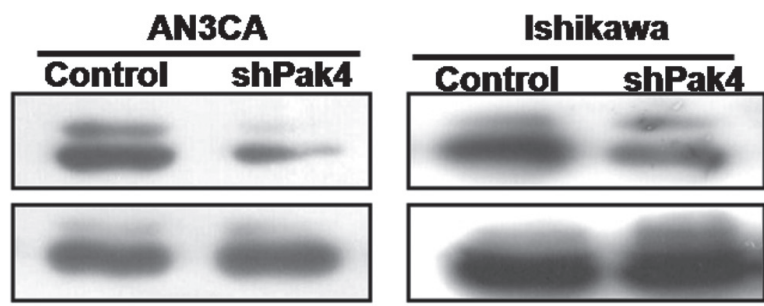

P-ERK1/2

ERK1/2

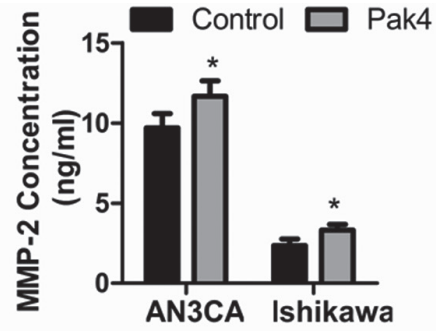

D
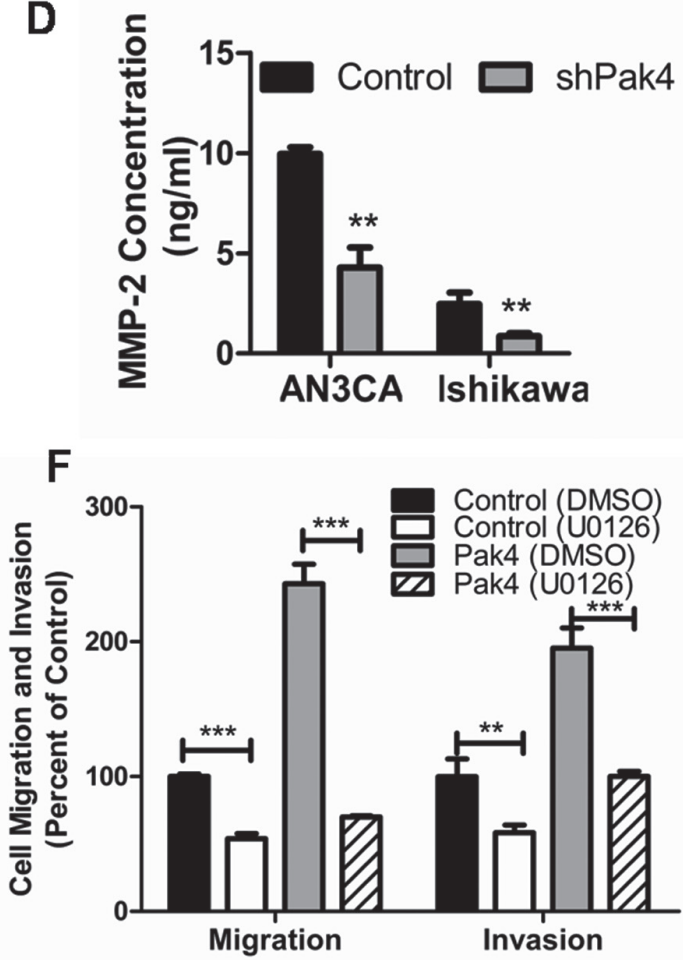

Figure 5. Pak4 regulation of EC cell migration and invasion involves the ERK1/2 pathway and MMP-2 secretion. (A and C) Western blot analysis of ERK1/2 activity (p-ERK1/2) in Pak4 overexpression and Pak4 knockdown AN3CA and Ishikawa cells. Expression of total ERK/1/2 (ERK1/2) as control. (B and D) ELISA analysis of MMP-2 secreted in the culture medium of Pak4 overexpression and Pak4 knockdown AN3CA, and Ishikawa cells. (E) U0126 inhibits MMP-2 secretion in EC cell lines; ${ }^{* *} P<0.001$. (F) In vitro migration and invasion assays in Ishikawa cells stably transfected with Pak4 or control vector in the presence or absence of U0126; $n=3 ;{ }^{* *} P<0.01,{ }^{* *} P<0.001$. All experiments were carried out in triplicate. 
effects of Pak4 on cell proliferation in short-term and longterm cultures.

The efficacy of anticancer therapies depends not only on the cellular damage they cause but also on the cell's ability to respond to these damages by inducing the apoptotic response [42]. Although we observed that Pak4 had no significant effect on EC cell apoptosis under regular culture conditions, Pak4 was found to protect HeLa and NIH3T3 cells from apoptosis induced by TNF- $\alpha$ and UV irradiation [43, 44]. In these cell lines, expression of Pak4 inhibits activation of caspase-3-like enzymes and specifically promotes the phosphorylation of $\mathrm{Bad}$ on serine 112 [44]. Another study showed that dual inhibition of Pak1 and inhibitor of apoptosis proteins (IAP) efficiently increased apoptosis of non-small cell lung cancer cell (NSCLC) cells[45]. Thus, inhibition of Pak4 may provide a promising therapeutic option to enhance radiation and chemotherapy sensitivity of metastatic endometrial cancer. However, whether Pak4 is involved in protecting endometrial cancer cells from apoptosis induced by radiation or chemotherapy needs to be further elucidated.

In summary, our study demonstrates that overexpression and activation of Pak4 play important roles in endometrial cancer metastasis. We showed that Pak4 protein is overexpressed and activated in endometrial carcinoma, especially in the most advanced lesions. We also found that Pak4 affects EC cell migration and invasion in vitro. In addition, Pak4 regulates EC cell migration and invasion through through ERK1/2-mediated MMP-2 secretion. As Pak4 regulates both EC cell migration and invasion, making it obvious therapeutic targets for metastatic endometrial cancer.

Acknowledgments: This study was supported by Grants from the National Natural Science Funds of China (Nos. 81072139, 81172476 and 81272885). The authors thank Prof. Hui-Juan Zhang and Dr. Yuan Liu for pathology revision.

\section{References}

[1] SIEGEL R, WARD E, BRAWLEY O, JEMAL A. Cancer statistics, 2011. CA: A Cancer Journal for Clinicians 2011; 61: 212-236. http://dx.doi.org/10.3322/caac.20121

[2] WANG D, ZHENG W, WANG S-M, WANG J-B, WEI W-Q et al. Estimation of Cancer Incidence and Mortality Attributable to Overweight, Obesity, and Physical Inactivity in China. Nutrition and Cancer 2012; 64: 48-56. http://dx.doi. org/10.1080/01635581.2012.630166

[3] DEDES KJ, WETTERSKOG D, ASHWORTH A, KAYE SB, REIS-FILHO JS. Emerging therapeutic targets in endometrial cancer. Nature Reviews Clinical Oncology 2011; 8: 261-271. http://dx.doi.org/10.1038/nrclinonc.2010.216

[4] LEE NK. Adjuvant treatment of advanced-stage endometrial cancer. Clin Obstet Gynecol 2011; 54: 256-265. http://dx.doi. org/10.1097/GRF.0b013e318218c659

[5] KUMAR R, GURURAJ AE, BARNES CJ. p21-activated kinases in cancer. Nature Reviews Cancer 2006; 6: 459-471. http://dx.doi.org/10.1038/nrc1892
[6] WHALE A, HASHIM FN, FRAM S, JONES GE, WELLS CM. Signalling to cancer cell invasion through PAK family kinases. Front Biosci 2011; 16: 849-864. http://dx.doi. org/10.2741/3724

[7] ESWARAN J, SOUNDARARAJAN M, KUMAR R, KNAPP S. UnPAKing the class differences among p21-activated kinases. Trends in Biochemical Sciences 2008; 33: 394-403. http://dx.doi.org/10.1016/j.tibs.2008.06.002

[8] BASKARAN Y, NG YW, SELAMAT W, LING FT, MANSER E. Group I and II mammalian PAKs have different modes of activation by Cdc42. EMBO Rep 2012; 13: 653-659. http:// dx.doi.org/10.1038/embor.2012.75

[9] DUMMLER B, OHSHIRO K, KUMAR R, FIELD J. Pak protein kinases and their role in cancer. Cancer and Metastasis Reviews 2009; 28: 51-63. http://dx.doi.org/10.1007/s10555008-9168-1

[10] ABO A, QU J, CAMMARANO MS, DAN C, FRITSCH A et al. PAK4, a novel effector for Cdc42Hs, is implicated in the reorganization of the actin cytoskeleton and in the formation of filopodia. EMBO J 1998; 17: 6527-6540. http://dx.doi. org/10.1093/emboj/17.22.6527

[11] BARAC A, BASILE J, VAZQUEZ-PRADO J, GAO Y, ZHENG $Y$ et al. Direct interaction of $\mathrm{p} 21$-activated kinase 4 with PDZRhoGEF, a G protein-linked Rho guanine exchange factor. J Biol Chem 2004; 279: 6182-6189. http://dx.doi.org/10.1074/ jbc.M309579200

[12] CALLOW MG, ZOZULYA S, GISHIZKY ML, JALLAL B, SMEAL T. PAK4 mediates morphological changes through the regulation of GEF-H1. J Cell Sci 2005; 118: 1861-1872. http://dx.doi.org/10.1242/jcs.02313

[13] ZHANG H, LI Z, VIKLUND EK, STROMBLAD S. P21activated kinase 4 interacts with integrin alpha v beta 5 and regulates alpha v beta 5-mediated cell migration. J Cell Biol 2002; 158: 1287-1297. http://dx.doi.org/10.1083/ jcb.200207008

[14] LIZ, LOCK JG, OLOFSSON H, KOWALEWSKI JM, TELLER $S$ et al. Integrin-mediated cell attachment induces a PAK4dependent feedback loop regulating cell adhesion through modified integrin alpha $\mathrm{v}$ beta 5 clustering and turnover. Mol Biol Cell 2010; 21:3317-3329. http://dx.doi.org/10.1091/mbc. E10-03-0245

[15] SOOSAIRAJAH J, MAITI S, WIGGAN O, SARMIERE $\mathrm{P}$, MOUSSI N et al. Interplay between components of a novel LIM kinase-slingshot phosphatase complex regulates cofilin. EMBO J 2005; 24: 473-486. http://dx.doi.org/10.1038/ sj.emboj.7600543

[16] DAN C, KELLY A, BERNARD O, MINDEN A. Cytoskeletal changes regulated by the PAK4 serine/threonine kinase are mediated by LIM kinase 1 and cofilin. J Biol Chem 2001; 276: 32115-32121. http://dx.doi.org/10.1074/jbc.M100871200

[17] AHMED T, SHEA K, MASTERS JRW, JONES GE, WELLS CM. A PAK4-LIMK1 pathway drives prostate cancer cell migration downstream of HGF. Cellular Signalling 2008; 20: 1320-1328. http://dx.doi.org/10.1016/j.cellsig.2008.02.021

[18] SIU MK, CHAN HY, KONG DS, WONG ES, WONG OG et al. p21-activated kinase 4 regulates ovarian cancer cell proliferation, migration, and invasion and contributes to poor 
prognosis in patients. Proc Natl Acad Sci U S A 2010; 107: 18622-18627. http://dx.doi.org/10.1073/pnas.0907481107

[19] ZHANG HJ, SIU MK, YEUNG MC, JIANG LL, MAK VC et al. Overexpressed PAK4 promotes proliferation, migration and invasion of choriocarcinoma. Carcinogenesis 2011; 32: 765-771. http://dx.doi.org/10.1093/carcin/bgr033

[20] CALLOW MG. Requirement for PAK4 in the Anchorageindependent Growth of Human Cancer Cell Lines. Journal of Biological Chemistry 2001; 277: 550-558. http://dx.doi. org/10.1074/jbc.M105732200

[21] LI X, KE Q, LI Y, LIU F, ZHU G et al. DGCR6L, a novel PAK4 interaction protein, regulates PAK4-mediated migration of human gastric cancer cell via LIMK1. Int J Biochem Cell Biol 2010; 42: 70-79. http://dx.doi.org/10.1016/j.biocel.2009.09.008

[22] MAK GW, CHAN MM, LEONG VY, LEE JM, YAU TO et al. Overexpression of a novel activator of PAK4, the CDK5 kinase-associated protein CDK5RAP3, promotes hepatocellular carcinoma metastasis. Cancer Res 2011; 71: 2949-2958. http://dx.doi.org/10.1158/0008-5472.CAN-10-4046

[23] LIU Y, XIAO H, TIAN Y, NEKRASOVA T, HAO X et al. The Pak4 Protein Kinase Plays a Key Role in Cell Survival and Tumorigenesis in Athymic Mice. Molecular Cancer Research 2008; 6: 1215-1224. http://dx.doi.org/10.1158/1541-7786. MCR-08-0087

[24] ZHANG L, REES MC, BICKNELL R. The isolation and longterm culture of normal human endometrial epithelium and stroma. Expression of mRNAs for angiogenic polypeptides basally and on oestrogen and progesterone challenges. J Cell Sci 1995; 108 (Pt 1): 323-331.

[25] OSTEEN KG, HILL GA, HARGROVE JT, GORSTEIN F. Development of a method to isolate and culture highly purified populations of stromal and epithelial cells from human endometrial biopsy specimens. Fertil Steril 1989; 52: 965-972.

[26] NISHIDA M. The Ishikawa cells from birth to the present. Hum Cell 2002; 15: 104-117. http://dx.doi.org/10.1111/j.17490774.2002.tb00105.x

[27] DAWE CJ, BANFIELD WG, MORGAN WD, SLATICK MS, CURTH HO. Growth in Continuous Culture, and in Hamsters, of Cells from a Neoplasm Associated with Acanthosis Nigricans. J Natl Cancer Inst 1964; 33: 441-456.

[28] PARK MH, LEE HS, LEE CS, YOU ST, KIM DJ et al. p21-Activated kinase 4 promotes prostate cancer progression through CREB. Oncogene 2012.

[29] CREASMAN WT, MORROW CP, BUNDY BN, HOMESLEY HD, GRAHAM JE et al. Surgical pathologic spread patterns of endometrial cancer. A Gynecologic Oncology Group Study. Cancer 1987; 60: 2035-2041. http://dx.doi. org/10.1002/1097-0142(19901015)60:8+<2035::AIDCNCR2820601515>3.0.CO;2-8

[30] CREASMAN W. Revised FIGO staging for carcinoma of the endometrium. International Journal of Gynecology \& Obstetrics 2009; 105: 109. http://dx.doi.org/10.1016/ j.ijgo.2009.02.010

[31] UHARCEK P. Prognostic factors in endometrial carcinoma. Journal of Obstetrics and Gynaecology Research 2008; 34: 776-783. http://dx.doi.org/10.1111/j.1447-0756.2008.00796.x
[32] DI CRISTOFANO A, ELLENSON LH. Endometrial Carcinoma. Annual Review of Pathology: Mechanisms of Disease 2007; 2: 57-85. http://dx.doi.org/10.1146/annurev. pathol.2.010506.091905

[33] LEE SR. AR and ER Interaction with a p21-Activated Kinase (PAK6). Molecular Endocrinology 2002; 16: 85-99. http:// dx.doi.org/10.1210/me.16.1.85

[34] GURURAJ AE. Novel Mechanisms of Resistance to Endocrine Therapy: Genomic and Nongenomic Considerations. Clinical Cancer Research 2006; 12: 1001s-1007s. http://dx.doi. org/10.1158/1078-0432.CCR-05-2110

[35] WELLS CM. PAK4 is activated via PI3K in HGF-stimulated epithelial cells. Journal of Cell Science 2002; 115: 3947-3956. http://dx.doi.org/10.1242/jcs.00080

[36] QU J, CAMMARANO MS, SHI Q, HA KC, de LANEROLLE $\mathrm{P}$ et al. Activated PAK4 regulates cell adhesion and anchorage-independent growth. Mol Cell Biol 2001; 21: 3523-3533. http://dx.doi.org/10.1128/MCB.21.10.3523-3533.2001

[37] LI Z, LOCK JG, OLOFSSON H, KOWALEWSKI JM, TELLER $S$ et al. Integrin-mediated Cell Attachment Induces a PAK4dependent Feedback Loop Regulating Cell Adhesion through Modified Integrin v 5 Clustering and Turnover. Molecular Biology of the Cell 2010; 21: 3317-3329. http://dx.doi.org/ 10.1091/mbc.E10-03-0245

[38] QU J, LI X, NOVITCH BG, ZHENG Y, KOHN M et al. PAK4 kinase is essential for embryonic viability and for proper neuronal development. Mol Cell Biol 2003; 23: 7122-7133. http://dx.doi.org/10.1128/MCB.23.20.7122-7133.2003

[39] HOOD JD, CHERESH DA. Role of Integrins in Cell Invasion and Migration. Nature Reviews Cancer 2002; 2: 91-100. http://dx.doi.org/10.1038/nrc727

[40] DECOCK J, THIRKETTLE S, WAGSTAFF L, EDWARDS DR. Matrix metalloproteinases: protective roles in cancer. J Cell Mol Med 2011; 15: 1254-1265. http://dx.doi.org/10.1111/ j.1582-4934.2011.01302.x

[41] THUllberG M, GAD A, BEESER A, CHERNOFF J, STROMBLAD S. The kinase-inhibitory domain of p21activated kinase 1 (PAK1) inhibits cell cycle progression independent of PAK1 kinase activity. Oncogene 2007; 26: 1820-1828. http://dx.doi.org/10.1038/sj.onc.1209983

[42] CHAUDHRY P, ASSELIN E. Resistance to chemotherapy and hormone therapy in endometrial cancer. Endocrine Related Cancer 2009; 16: 363-380. http://dx.doi.org/10.1677/ERC$\underline{08-0266}$

[43] LI X. PAK4 Functions in Tumor Necrosis Factor (TNF) -induced Survival Pathways by Facilitating TRADD Binding to the TNF Receptor. Journal of Biological Chemistry 2005; 280: 41192-41200. http://dx.doi.org/10.1074/jbc.M506884200

[44] GNESUTTA N, QU J, MINDEN A. The serine/threonine kinase PAK4 prevents caspase activation and protects cells from apoptosis. J Biol Chem 2001; 276: 14414-14419.

[45] ONG CC, JUBB AM, HAVERTY PM, ZHOU W, TRAN V et al. Targeting p21-activated kinase 1 (PAK1) to induce apoptosis of tumor cells. Proceedings of the National Academy of Sciences 2011; 108: 7177-7182. http://dx.doi.org/10.1073/ pnas. 1103350108 